Extended Abstract

\title{
Embodied cognition and information
}

Derek Jones ${ }^{1, *}$

${ }^{1}$ Department of Engineering and Innovation, Faculty of Mathematics, Computing and Technology, The Open University, Walton Hall, Milton Keynes, MK7 6AA

E-Mails: derek.jones@open.ac.uk

* Author to whom correspondence should be addressed;

Accepted:

No bits were destroyed in the making of this paper. This statement is a lie.

This paper explores the nature of information by bringing together two questions posed by Luciano Floridi in his 'Open problems' paper [1].

Firstly:

P.4: DGP, the data-grounding problem: How can data acquire their meaning?

(and the later question Can PI [Philosophy of Information] explain how the mind conceptualises reality?)

and

P.11: The MIB (mind-information-body) problem: Can an informational approach solve the mindbody problem?

In the first question, Floridi refers to work by Searle [2] and Mingers [3]. Interestingly, no reference is made to either author for the second question, considering that both have made relevant and interesting contributions to this question specifically.

For Searle, there is no more a mind-body problem than any other dualism we choose to create semantically: it is a construct of concept, nothing more. For Mingers, a similar conclusion is reached by applying a phenomenological approach to Artificial Intelligence: that a disembodied intelligence is a contradiction. In both cases, the mind and body are one - it is not possible to escape acknowledging that thoughts arise from a physical (cognitive) process.

This position has a resonance to Landauer's [4] view of information as an 'inevitably' physical entity; that at some point, all information is embodied. By this view, information remains a Shannonlike definition, a deterministic part of the embodied model where notions of semantic information are 
(almost) ignored. But simply because information is embodied, it does not follow that information is an object in and of itself, only that what we define it to be such under the condition of its physical embodiment. Once again, what might have been a simple theory is interrupted by semantic conception.

More recent developments in information theory have focused on semantic information and its essentially human construction and use. The Difference that Makes a Difference conferences place this as a specific focus in terms of information in human meaning and value. And this, too arises, form a pragmatic tradition and approach: what is the point, utility, use, purpose of information and how might such explorations help 'define' it?

So we have two views of information that both arise from a pragmatic starting point: the first observes simply that information is physically embodied; the second that, at some point, information is defined and construed by people (a necessary part of both the ontology and epistemology). But both views also have another feature that will be used as the focus of this paper: they both make use of embodiment in some way: embodying information or cognition in the physical world.

It is argued that embodiment of information and the embodied mind present a valuable 'place' to explore the nature of information. In fact, an inversion to Floridi's $11^{\text {th }}$ problem is proposed : 'can an embodied mind shed light on P.1: What is information'?

The paper will present a series of examples of argument construction that use embodiment to explore the nature of information, considering: embodiment itself, embodied cognition and embodied information. Examples of possible approaches are now given for each.

\section{General embodiment}

General embodiment can allow more nuanced views and approaches in constructing arguments and ideas. For example, if we begin with Merleau-Ponty's embodiment in phenomenology [5], we must then accept that the simple model of 'one thing leading to another' (as defined semantically and at a certain scale) cannot be used in construction of arguments: embodiment supposes that dualities such as perception and thought are embodied and happen 'together' (not necessarily synchronously). This removal of duality has an immediate consequence for the epistemology of semantic information theory but it also offers an interesting speculation environment within which we might pose further questions. To apply this, the 'semantic scale' referred to becomes an essential condition under which definitions of both the ontology and epistemology of information are constructed (one recognized by Bell [6] at the quantum scale, for example). But it is the boundary of these scales that hopefully will prove useful in providing a space within which we might explore semantic and deterministic views of information outlined previously (or set limits on what we might know about such reconciliations).

\section{Embodied cognition}

Starting with an acceptance of embodied cognition, we have an immediate series of directions to turn in exploring information (see Wilson's summary presenting six views [7]). For example, considering Lakoff and Johnson's conceptual metaphors [8,9,10] (cognitive constructs that arise from our embodied understandings of the world around us) provides a starting point and conditions under which we might consider the nature of semantic information. This might be achieved simply (by defining semantic information in terms of embodied cognition) or it may be achieved by considering the processing that takes place in order to transfer, translate or re-apply such metaphors. That is, we are 
now interested in the transmission of conceptual metaphors as an expression of information. As with general embodiment, this represents a boundary space between the physical process of cognition (an embodied, physical act) and the conceptual process (the use of embodied metaphor as meaningful communication or transmission of information).

\section{Embodied information}

Another approach is to approach information as embodied in itself, accept Landauer's thesis [4], and follow the consequences of this to explore information as embodied in cognition. The interesting question that arises is at what point cognition becomes embodied information. For example, recent research in cognitive neuroscience shows that Broca's area (the part of the brain generally considered to be a main processing centre for speech) is actually less active whilst we speak [11], suggesting a necessary limit semantically - the translation of our ideas and conceptions to language results in change to those very ideas, as a result of the emergent nature of cognitive processes (for other examples see $[12,13,14])$. By this argument we have another embodiment of physical information and semantic information but this time in the same series of cognitive processes - both with very different approaches and understandings of information. Once again, it is the 'in-between' of these arguments that may provide an interesting space for speculation.

These outlines are given as examples only. The material point here is the construction of conceptual spaces within which further observation or understandings might be made - these are in some way a response to Floridi's P.16 sub-question, that information is neither here nor there but embodied between here and there. Any or all of these approaches may end in trivial or complex failure. In support of this, Floridi's points (after Hilbert) about the rigour of method(s) and the value of failure will be adopted.

Above all, this paper will be presented in the spirit of the Difference that makes a Difference - a conversational, collegiate discussion that seeks alternative views that hopefully allow new thoughts on information and its value to emerge.

\section{References and Notes}

1 Floridi, Luciano (2004) 'Open Problems in the Philosophy of Information.' Metaphilosophy, 35(4), pp. 554-582. [online] Available from: http://onlinelibrary.wiley.com/doi/10.1111/j.14679973.2004.00336.x/abstract/nhttp://doi.wiley.com/10.1111/j.1467-9973.2004.00336.x

2 Searle, John R. (1980) 'Minds, Brains, and Programs.' Behavioral and Brain Sciences, 3, pp. 1-19.

3 Mingers, John (1997) 'The Nature of Information and Its Relationship to Meaning.', in Winder, R. L., Probert, S. K., and Beeson, I. A. (eds.), Philosophical Aspects of Information Systems., London, Taylor \& Francis. [online] Available from:

https://books.google.co.uk/books?id=lsJo2P3QvMQC\&pg=PA73\&lpg=PA73\&dq=The+nature + o $\mathrm{f}+$ information + and + its + relationship + to + meaning, + john + mingers\&source $=$ bl\&ots $=$ aGXQNxsV\&sig=8usmA_wcxbf_M10fsT6cFNSslxE\&hl=en\&sa=X\&ei=d0PuVP7aJ6bj7Qak9IHIBA\& $\mathrm{ved}=0 \mathrm{CDAQ6AEwAQ \# v=tw}$

4 Landauer, Rolf (1996) 'The physical nature of information.' Physics Letters, Section A: General, Atomic and Solid State Physics, 217(July), pp. 188-193. 
5 Merleau-Ponty, M (1962) Phenomenology of perception, London: Routledge \& Kegan Paul.

6 Bell, John S. (1964) 'On the Einstein Podolsky Rosen Paradox.' Physics, 1, pp. 195-200.

7 Wilson, Margaret (2002) 'Six views of embodied cognition.' Psychonomic bulletin \& review, 9(4), pp. 625-36. [online] Available from: http://www.ncbi.nlm.nih.gov/pubmed/12613670

8 Lakoff, George and Johnson, Mark (1980) Metaphors We Live by, University of Chicago Press.

9 Johnson, Mark and Lakoff, George (2002) 'Why cognitive linguistics requires embodied realism.' Cognitive Linguistics, 13(3), pp. 245-263.

10 Lakoff, George and Johnson, Mark (1999) Philosophy in the Flesh: The Embodied Mind and Its Challenge to Western Thought, New York, Basic Books.

11 Flinker, Adeen, Korzeniewska, Anna, Shestyuk, Avgusta Y., Franaszczuk, Piotr J., et al. (2015) 'Redefining the role of Broca's area in speech.' Proceedings of the National Academy of Sciences. [online] Available from:

http://www.pnas.org/content/early/2015/02/09/1414491112.abstract (Accessed 19 February 2015)

12 Ariely, Dan (2012) The (Honest) Truth About Dishonesty 1st ed., New York, HarperCollins.

13 Mlodinow, Leonard (2012) Subliminal The New Unconscious and What it Teaches Us 1st ed., London, Penguin Books.

14 Schooler, Jonathan W and Engstler-Schooler, Tonya Y (1990) 'Verbal overshadowing of visual memories: Some things are better left unsaid.' Cognitive Psychology, 22(1), pp. 36-71. [online] Available from: http://linkinghub.elsevier.com/retrieve/pii/001002859090003M

(C) 2015 by the authors; licensee MDPI and ISIS. This abstract is distributed under the terms and conditions of the Creative Commons Attribution license. 